\title{
Um iluminista na aldeia dos Tupinambás
}

A História da Cidade do Rio de Janeiro sob a ótica de Delgado de Carvalho Un illuministe dans le village des Tupinambas: 1 ' 'histoire de la ville de Rio de sous la perspective de Delgado de Carvalho

Un ilustrado en la aldea de los Tupinambás: la Historia de la Ciudad de Río de Janeiro según Delgado de Carvalho

An Enlightenment in the Tupinambás Village: History of the City of Rio de Janeiro from the perspective of Delgado de Carvalho

\section{Leonardo Civale}

\section{(2) OpenEdition}

Journals

Edição electrónica

URL: https://journals.openedition.org/terrabrasilis/3212

DOI: $10.4000 /$ terrabrasilis.3212

ISSN: 2316-7793

Editora

Rede Brasileira de História da Geografia e Geografia Histórica

Refêrencia eletrónica

Leonardo Civale, «Um iluminista na aldeia dos Tupinambás», Terra Brasilis [Online], 10 | 2018, posto online no dia 26 dezembro 2018, consultado o 05 dezembro 2022. URL: http://

journals.openedition.org/terrabrasilis/3212 ; DOI: https://doi.org/10.4000/terrabrasilis.3212

Este documento foi criado de forma automática no dia 5 dezembro 2022.

All rights reserved 


\title{
Um iluminista na aldeia dos Tupinambás
}

\author{
A História da Cidade do Rio de Janeiro sob a ótica de Delgado de Carvalho \\ Un illuministe dans le village des Tupinambas: I'histoire de la ville de Rio de sous \\ la perspective de Delgado de Carvalho \\ Un ilustrado en la aldea de los Tupinambás: la Historia de la Ciudad de Río de \\ Janeiro según Delgado de Carvalho \\ An Enlightenment in the Tupinambás Village: History of the City of Rio de \\ Janeiro from the perspective of Delgado de Carvalho
}

\section{Leonardo Civale}

\section{Introdução}

1 Em uma pesquisa sobre os intelectuais e a memória das cidades, cujo objetivo era investigar o papel dos intelectuais na construção da memória do Rio de Janeiro, nos deparamos com o livro História da Cidade do Rio de Janeiro, de Delgado de Carvalho. ${ }^{1} \mathrm{O}$ texto foi publicado originalmente em 1926 e teve uma edição comemorativa em 1988, no aniversário de fundação da cidade. No primeiro prefácio do livro, escrito por Carlos Augusto Addor, o autor destaca o momento pelo qual passava o país quando da publicação e os elementos que revelariam a concepção de historiografia de Delgado de Carvalho. No segundo prefácio, a autora Therezinha de Castro, assistente de Delgado de Carvalho, chama a atenção para a homenagem feita pelo autor ao prefeito Pereira Passos e a Alfredo Américo de Souza Rangel, sua destacada atuação como educador, bem como, o propósito do livro. O livro teria a função de introduzir os estudantes na história da cidade do Rio de Janeiro, uma vez que, o programa relativo ao antigo $4^{\circ}$ ano primário tratava a História da Cidade do Rio de Janeiro, capital da República à época, como introdução à História do Brasil.

2 É necessário destacar que o livro foi escrito em uma época de profundas transformações urbanas, cujo auge haveria de ser a retirada do morro do Castelo no centro da cidade. A 
leitura do texto provocou questões que deram origem ao artigo. 0 artigo é um exercício historiográfico e geográfico cujo principal objetivo é compreender o processo de constituição do saber sobre a história da cidade, levando em consideração não apenas as inclinações políticas e suas relações com eminentes figuras da vida da cidade, mas também suas opções teóricas e metodológicas.

Portanto, não se trata de apenas integrar o pensador em uma categoria mais ampla de intelectuais no pensamento social brasileiro, tampouco de uma reflexão sobre o período histórico em que o livro foi publicado. Ainda que estas questões não sejam negligenciadas, o artigo discute a maneira de se escrever a história da cidade a partir da abordagem teórica e metodológica do autor. Em outras palavras, o artigo tem o objetivo de compreender como, Delgado de Carvalho se apropriava do saber histórico e geográfico de sua época sobre o lugar e o tempo e, de que maneira se munia de seu saber para se inserir na vida social, política e cultural da cidade. O artigo visa compreender como se construiu uma versão da história da cidade que se confundia com os ícones da cultura moderna dos anos 20 do século XX. A formação intelectual de Delgado de Carvalho, os objetivos do livro, a concepção de como fazer história e geografia e a relação com figuras políticas do período ajudam a compreender a interpretação do autor sobre a história de um lugar: a cidade do Rio de Janeiro.

\section{Para Delgado de Carvalho o passado não era um país estrangeiro}

Em 1953, o escritor inglês L.P. Hartley começava seu romance $O$ mensageiro com a seguinte epígrafe "O passado é um país estrangeiro. Lá eles fazem as coisas de maneira diferente." Em 1971, o livro seria levado às telas com direção de Joseph Losey e adaptação de Harold Pinter. Em 1995, no livro Como conhecemos o passado, David Lowenthal se reportaria ao escritor para fazer referência ao passado. Em 2015, Peter Burke historiador inglês, no livro 0 que é História cultural?, também revisitava a obra de Hartley. ${ }^{2}$

O livro História da cidade do Rio de Janeiro de Delgado de Carvalho, publicado em 1926, pode ser considerado o primeiro trabalho de história da cidade feito por um profissional com formação acadêmica na área. Tal fato, por si só, já o tornaria digno de relevo. No entanto, as opções teóricas e metodológicas do autor o transformam em um material incontornável para todos aqueles que se interessam pela história da geografia, geografia histórica, história das cidades, história do urbanismo e áreas afins.

6 A questão a nos guiar neste artigo se refere às opções teóricas e metodológicas da geografia histórica ou da história da geografia e, esta, por sua vez, está relacionada à forma como este ramo ou, estes ramos, do saber geográfico se debruçam sobre o passado. A construção de um campo de saber na geografia, ou de dois se preferirem, a geografia histórica e a história da geografia passam de maneira incontornável sobre o conhecimento do passado.

7 Escrito na perspectiva dos anos 20 do século XX, o livro se divide em oito capítulos e percorre a história da cidade desde a sua fundação, pelos portugueses, em 1565, após uma disputa com os franceses, até aquele momento que, na perspectiva do autor, viria a ser o ápice da antiga capital federal: o governo do prefeito Pereira Passos. 
8 No prefácio do livro Delgado de Carvalho deixa clara as suas credenciais de educador engajado na renovação da historiografia e da geografia brasileiras e na formação de quadros do magistério do antigo Distrito Federal, uma vez que situa o trabalho, sobre a história da então capital da República, como uma introdução à História do Brasil. Para Delgado de Carvalho, naquilo que seria a adoção do método de círculos concêntricos do programa de História do Brasil, a História do Rio de Janeiro teria um enorme valor didático. No primeiro parágrafo do prefácio, portanto, Delgado de Carvalho revela o seu comprometimento historicista ao exaltar o valor didático:

É pois, de grande valor didático que venha a ser preliminarmente dados aos alunos um apanhado histórico cujos elementos principais, locais, monumentos e vestígios, estão ainda às nossas vistas, ao alcance de nossos sentidos e podem muito mais facilmente impressionar jovens imaginações, do que outras narrações, cujos quadros necessitam de um esforço do espírito para a sua reconstituição. ${ }^{3}$

9 No entanto, o autor também deixa claro, a sua filiação ao rigor empregado pela historiografia francesa, na qual foi formado, à medida que, ainda na introdução, revela as suas extensas fontes bibliográficas. Ao final do livro o autor elenca uma bibliografia comentada visando facilitar a consulta de fontes primárias e secundárias.

10 Delgado de Carvalho, recorrendo ao que seria uma moderna orientação historiográfica, recusa o uso da mnemotécnica, ou seja, embora não haja nenhuma vinculação entre ele e aquilo que mais tarde viria ser conhecido como a École des Annalles, o autor repudia a historiografia tradicional e orienta a sua historiografia como um quadro de épocas sucessivas. Com isso, Delgado de Carvalho acreditava que seria possível compreender a atuação dos atores políticos e sociais dentro do quadro político de uma época específica. Ainda que essa metodologia esteja distante daquilo que seria uma história social moderna, não há como negar que Delgado de Carvalho avança em relação às concepções de sua época.

11 No que diz respeito ao espaço, o autor não nega a sua orientação positivista e, como o livro procura sintetizar a história da cidade do Rio de Janeiro, esta aparece como um belo cenário para o teatro da política. Em outras palavras, uma espécie de anfiteatro construído entre o mar e as montanhas onde o drama ou a comédia dos acontecimentos políticos vão ser encenados.

12 A concepção de história de Delgado de Carvalho, que de certo modo antecipa algumas concepções da moderna historiografia francesa, levada a cabo um pouco mais tarde por Marc Bloch e Lucien Febvre, permite ao autor ir além daquilo que normalmente a historiografia tradicional, marcada pelo positivismo metódico e pelo comprometimento de classe, jamais conseguiria. o livro, portanto, ainda que prometa mais do que realmente cumpre, aponta para a emergência de uma história social ao se referir às condições de vida, às tradições, aos costumes e às festas da população carioca ao longo de sua história.

13 Mesmo em se tratando da história política, há que se destacar a visão moderna de Delgado de Carvalho, afeita à renovação provocada pela explosão de ideias da década de 1920. Para Delgado de Carvalho, como o livro demonstra, a história política deve levar em consideração alguns nomes e datas. No entanto, estas são importantes apenas na medida em que, revelam a sucessão de tempos, de épocas e de eras. A história política da cidade deveria, portanto, privilegiar as preocupações da própria população ao longo do tempo e, estas, se concentravam na defesa, na política exterior, nas ideias de metrópole e nos monumentos nacionais: 
A história do Rio de Janeiro não é a história de seus governadores, de seus vice-reis, de seus monarcas, presidentes e prefeitos: algumas datas célebres, alguns nomes importantes podem e devem marcar etapas na sucessão dos tempos, no desenrolar dos acontecimentos; mas os assuntos capitais dessa história são as condições de vida dos próprios cariocas, em diferentes épocas, suas tradições, seus costumes, seus usos, suas necessidades e suas festas. ${ }^{4}$

Em relação aos monumentos da cidade, entretanto, Delgado de Carvalho pagaria o preço da filiação a uma historiografia mais tradicional ao associar monumento ao documento. Para o autor o monumento se confunde com o documento e, portanto, deve ser analisado como tal. Delgado de Carvalho compreende os monumentos urbanos como uma espécie de memória congelada em pedra e cal. Para o autor, a memória da população não estaria necessariamente relacionada à beleza arquitetônica ou a imponência do monumento, "mas, sobretudo, mais ao feixe de lembranças que se prendem às pedras superpostas, como raízes adventícias de hera, símbolo do tempo que passa, mas não morre na memória das coisas". ${ }^{5}$

Desta feita, os monumentos no espaço da cidade seriam parte de uma pedagogia inscrita sob a forma de pedra e cal na paisagem urbana. Neste caso, o dever do mestre seria fomentar a imaginação dos estudantes no sentido de nutrir o espírito nacional e fortalecer a relação de reciprocidade e a noção de pertencimento entre a sociedade e a cidade:

Cada vez que pode um pensamento ou um acontecimento ficar ligado a um monumento histórico, é dever do mestre, procurar evocar nas jovens imaginações o quadro histórico que centralizou. É na interpretação destas páginas de pedra e de ferro que se gravam mais profundamente na memória os acontecimentos que tiveram real alcance. ${ }^{6}$

Delgado de Carvalho compreende o tempo como um elo entre o presente e o passado. No tempo visto como um continuum a explicação do presente estaria invariavelmente ligada ao passado. O passado seria parte de um corpo que cresce e evolui. Na historiografia de Delgado de Carvalho passado e presente estariam condenados a viver como irmãos siameses. Neste caso, a cidade seria a concretização na sua urbanização, nas suas realizações arquitetônicas, nos seus monumentos, dos desígnios da nação. No espaço concreto da cidade estaria, portanto, inscrita a genealogia da nação. Saber ler e interpretar as paisagens urbanas coalhadas de monumentos que encarnam a história da nação seria a máxima expressão de um dever cívico. Amar a cidade, os seus monumentos e reconhecer os esforços sobre humanos para transformá-la em um cenário da civilização ocidental seria o primeiro passo para amar a nação. Caberia, portanto, ao mestre o papel não apenas de intérprete e conhecedor da paisagem urbana, mas, sobretudo, daquele que seria capaz de fazer florescer, através da paisagem urbana, o amor pelas coisas da pátria. Tal amor fraternal seria uma realidade concreta, na medida em que, o mestre fizesse brotar na criança o sentimento de solidariedade e pertencimento, o cimento necessário para a construção da nação.

Para Delgado de Carvalho a história da nação teria o condão de despertar a verdadeira "comunidade imaginada":?

Ao mestre a quem cabe o primeiro ensinamento de história nacional a uma criança, é dada uma missão sublime: é o despertar de uma inteligência, o desabrochar de uma alma às coisas da Pátria [...] Ao amor e à dedicação é necessário juntar-se o entusiasmo: aí nestas horas decisivas da vida do cidadão, deve vibrar a corda sensível da solidariedade nacional. A criança deverá ter a compreensão de que faz parte de um todo, uma nação, e que se acha ligada a um longo passado, 
representado pelos que lhe prepararam a sua missão. Esta solidariedade com o passado, evocando responsabilidade no futuro, é o laço mais forte do patriotismo. Raça, língua, religião, nada pode lhe ser comparado em força de coesão, para a criação de um espírito nacional. ${ }^{8}$

\section{A história da cidade como a narrativa do moderno}

Se os períodos de crise reforçam a procura por identidade, esta, por sua vez, tem o condão de despertar as forças que se encarregam de memórias que permaneciam adormecidas. 0 que se procurava investigar, no período em que o livro apareceu seria a relação entre a emergência da memória e a questão da identidade. A busca ávida por identidade, ou a reconstrução do saber como base na escala local da história da cidade é quase um mantra em um cenário de modernização.

Curiosamente, no entanto, o mesmo fenômeno que provocara a emergência de uma geografia histórica também a conduziria ao afastamento dos pressupostos teóricos e metodológicos das ciências históricas. Por um lado, este mesmo movimento, levou o saber geográfico a se aproximar da filosofia da história, por outro, levou o mesmo saber a privilegiar a história dos acontecimentos. A vinculação do autor à historiografia e a geografia francesas era inquestionável, no entanto, essa herança não seria suficiente para afastá-lo da história positivista do século XIX. A história positivista consagrava o fato e se sustentava numa crença ilusória da cronologia dos acontecimentos. Em outras palavras, o "calcanhar de Aquiles" da geografia histórica produzida pelo autor é ter se aproximado da filosofia da história e virado as costas para a historiografia moderna produzida na França por Lucien Febvre e Marc Bloch.

O trabalho em tela de Delgado de Carvalho é baseado na narrativa e na sequência temporal dos acontecimentos históricos procurando singularizar a formação da sociedade e da cidade do Rio de Janeiro. Nele, transparece o desejo explícito de retornar às origens da nação e de reconstruir a formação da cidade. No entanto, exceto para a perspectiva positivista ou historicista clássica, respeitar a cronologia ou a sequência dos acontecimentos não pressupõe uma resposta de valor heurístico em si.

tho de Delgado de Carvalho revela um olhar retrospectivo sobre a disciplina na medida em que se debruça sobre a história do saber geográfico e a historiografia e busca construir a história da cidade refutando aquilo que seria uma perspectiva tradicional. À primeira vista, em sua obra, tanto a geografia histórica como a história da geografia dialogariam com a historiografia moderna. No entanto, levando em consideração a metodologia e a teoria da história contemporânea, essa promessa não seria cumprida.

Quanto à aproximação entre o saber geográfico e a filosofia da história estamos nos referindo, evidentemente, não à historiografia moderna, mas a uma filosofia da história, que de acordo com as crenças iluministas, se ancorava na ideia de progresso. 0 maior problema das filosofias da história é pensar que existe um sentido na história, bem como o maior problema do positivismo é acreditar que os fatos ou acontecimentos existem independentes daqueles que os interpretam.

Assim, o grande desafio da geografia histórica de Delgado de Carvalho seria virar as costas para as filosofias da história, bem como, para o positivismo e abrir um diálogo com a moderna história social da cultura. Ao negligenciar a dívida para com a historiografia, a história da cidade vive obcecada pelas origens. Por isso, a geografia 
histórica ou a história da cidade se repetem em relação aos mitos fundadores. Por isso, a geografia histórica e a história da cidade reproduzem as narrativas épicas, desde a origem ou fundação até os dias atuais, quando, na realidade, o melhor caminho seria investigar a gênese de diversas narrativas.

Além disso, a ausência de uma historiografia contemporânea brasileira nos procedimentos metodológicos gera uma sombra sobre as suas conclusões teóricas. Tal procedimento, por um lado, dificulta o entendimento deste debate e, por outro, segmenta o texto em duas partes, uma teórica e metodológica e outra empírica, tornando menos clara a sua compreensão.

o fato deste tipo de abordagem ter proporcionado um veio produtivo e extremamente rico, tanto para a historiografia ocidental, quanto para a geografia histórica, não significa, entretanto, que esteja desprovido de críticas.

Em se tratando das fontes, o trabalho de Delgado de Carvalho é extremamente rico, no entanto, o autor não se aventura nas críticas às fontes. Não basta fazer uso de fontes primárias para se escrever a historiografia. Antes de tudo é necessário criticar as fontes. Assim, é importante não confundir o fazer historiográfico, ou seja, o escrever a história, ato que exige crítica e interpretação, com o processo histórico.

27 A obra de Delgado de Carvalho constrói uma narrativa que privilegia de tal maneira a sucessão de épocas que a descontinuidade, conceito fundamental para a historiografia, parece sequer existir. A narrativa histórica do autor encerra todo o valor em uma dinâmica temporal que emerge reificada do texto. A investigação das bases de formação do território da cidade ou o avanço das forças produtivas revela o caráter evolutivo do seu pensamento. Continuidades e rupturas são fundamentais para o entendimento da história enquanto categoria de análise, todavia, somente a crítica da escrita da própria história, ou melhor, a crítica da historiografia, consegue evidenciar as descontinuidades ou rupturas no processo. Em outras palavras, Delgado de Carvalho usa o recurso da sucessão de tempos como explicação histórica, mas o fazer historiográfico implica em uma práxis que se traduz na investigação de arquivos e na discussão da historiografia.

O resultado da investigação dos arquivos e da inserção na historiografia é por si só, o melhor recurso para se evidenciar os conflitos, criticar as fontes e evitar a sedução do pensamento evolutivo. Privilegiar a sucessão de tempos como categoria explicativa, empalidece a dinâmica política e o espaço passa a ser compreendido como uma espécie de tábula rasa local dos interesses externos. Tal perspectiva obscurece a realidade e, embora se baseie na compreensão da totalidade, deixa escapar as minúcias da realidade local.

29 A opção teórica e metodológica de Delgado de Carvalho segue de maneira precisa e brilhante os passos e as intenções daqueles que construíram a cidade do Rio de Janeiro e deixaram uma herança cristalizada em pedra e em cal. No entanto, esta opção torna invisíveis outras histórias e silencia vozes que também participaram da construção deste imenso artefato cultural que é a cidade do Rio de Janeiro. Em outras palavras, o espaço humano é o resultado do encontro de diferentes histórias, ainda que quase sempre, a construção desse espaço humano tenha sido inevitavelmente, acompanhada de violência extrema. A cidade do Rio de Janeiro foi erguida por conquistadores, capitães e governadores, graças à escravidão africana e sob os escombros de culturas nativas. A sociedade carioca e a cidade do Rio de Janeiro são, literalmente, os resultados da conquista e da adaptação de um grupo adventício em um cenário tropical. É inquestionável a circunstância histórica de o país ser o resultado da expansão europeia 
para o ocidente, no entanto, caberia ao historiador iluminar a contribuição daqueles que foram tornados invisíveis pela própria história.

A grande erudição adquirida pelo autor ao longo de uma vida dedicada às letras propiciou um arsenal teórico e metodológico capaz de compreender a singularidade da cidade e explicar o processo histórico de adaptação de populações adventícias ao mundo tropical através da noção da conquista, transformação e progresso. Todavia, encarar a história como ideia de progresso é aceitar, ainda que de forma implícita, que este deve teve necessariamente um núcleo central e daí foi irradiado para os outros lugares. A história como ideia de progresso tem um sentido e, este sentido, conduz inevitavelmente, como uma saga épica, à narrativa dos "povos europeus com história" em direção aos lugares dos "povos sem história" e, portanto, sem narrativa. Esse modelo, na realidade, não se reduz apenas a uma simples abordagem, este modelo reforça o sentido da colonização e a subalternização dos "povos sem história".

Pensar os lugares, como tradicionalmente foi feito, não é, necessariamente, a mesma coisa que pensar as diferenças entre os lugares, pois investigar os lugares como o resultado de um processo histórico único é diferente de interpretar os lugares como o resultado do encontro de processos históricos distintos. Embora possa parecer apenas um jogo de linguagem, trata-se, na realidade, de uma mudança de perspectiva. Compreender os lugares como um fenômeno gerado por um processo histórico único tem o seu valor heurístico. No entanto, essa perspectiva não deve negligenciar os processos históricos distintos que geraram os lugares distintos.

\section{Quer ir ao passado? Então mostre o passaporte}

No início do século XX o desejo de identidade nas sociedades libertas do jugo colonial não apenas justificava a produção de uma história nacional como explicava o sucesso de uma filosofia da história positivista e historicista. Se utilizar da história como uma ideia de progresso, como o paradigma iluminista era a profissão de fé de vários historiadores do século XIX e início do século XX, pelo menos até a revolução historiográfica dos Annales. Além disso, a Segunda Guerra Mundial, o período de descolonização, e a multiplicação de sociedades multiétnicas iriam, cada vez mais, influenciar os trabalhos tanto dos historiadores egressos dos Annales quanto daqueles nutridos pela historiografia marxista. A historiografia abandonaria o positivismo e se aproximaria cada vez mais das ciências sociais, sobretudo da antropologia. O conhecimento do passado se ampliaria e se questionaria o movimento linear. Os historiadores perceberiam que é a narrativa que garante o significado. A ideia do presente como uma continuidade do passado passaria a ser problematizada. Visitar o passado requeria afastamento e não intimidade. $O$ passado se transformava em um país estrangeiro.

A necessidade de fontes empíricas continua incontornável, porém estas não fornecem todas as informações. O trabalho daquele que se dedica ao passado é contestar narrativas pretéritas. Os fatos históricos não têm realidade objetiva, ou melhor, eles existem apenas como reconstrução, portanto, o conhecimento histórico é sempre subjetivo. $O$ passado não existe sem os historiadores, pois são estes que colocam a narrativa e a cronologia no passado. A narrativa histórica estabelece e controla o ritmo do tempo. A história não pode se confundir com a evolução urbana, nem com a trajetória da cidade, nem tampouco deve pensar o tempo de maneira linear ou progressiva. 

revelou totalmente comprometido com os ventos que traziam os novos tempos nas duas primeiras décadas do século XX e, talvez por este motivo, ele tenha sido seduzido pela explicação cronológica e pela filosofia da história. Uma filosofia que garantia um sentido à história da cidade, que prometia evolução, que acenava com a modernidade. Consequentemente, esta abordagem sombreou a perspectiva de Delgado de Carvalho no que diz respeito à crítica dos novos paradigmas que estavam sendo implantados na ótica da importação, reformulação ou apropriação de modelos externos de intervençães urbanas e sociais de sua época. A abordagem teórica e metodológica de Delgado de Carvalho levou o autor não apenas a negligenciar questões fundamentais para a compreensão da singularidade da formação social e da cidade como a reproduzir e reforçar a noção de influências que, de certa maneira, menosprezaram a formação do pensamento social no Brasil. 

como os homens do passado organizavam seus pensamentos e seu mundo conceitual, como expressavam as suas paixões e como participavam dos debates políticos. Na aurora da modernidade no Brasil, Delgado de Carvalho reconstrói o passado, mas não consegue perceber as incongruências do presente. As novas ideias apresentavam uma janela para a subjetividade, mas o autor optou por outro caminho. Ao reconstruir o caminho das narrativas que levaram à produção do espaço urbano do Rio de Janeiro, a maneira como este foi produzido, o autor flertou com a possibilidade de atingir as subjetividades, mas, na encruzilhada, optou pela cronologia das velhas positividades. Delgado de Carvalho esbarrou nas subjetividades subalternizadas, mas, seduzido pela racionalidade instrumental da modernidade, virou-lhes às costas. saber que se martirizava ante duas matrizes conceituais distintas: uma das ciências humanas e outra das ciências naturais. Com este instrumental teórico, como compreender quais motivos justificam que os homens tenham agido de uma maneira $\mathrm{e}$ não de outra? Quais as horizontalidades que os orientava no seu tempo? o que os teria levado a agir de uma maneira e não de outra? Quais as consequências humanas ao se optar por um modelo de modernização ancorado em uma racionalidade instrumental e não por outro, mais afeito às necessidades da população?

No livro A História da cidade do Rio de Janeiro, Delgado de Carvalho segura com as duas mãos a explicação de como o território foi construído, a paisagem foi transformada e o lugar foi definido ao longo de quatro séculos da história da cidade. Todavia, o autor deixa escorrer entre os dedos as razões, as paixões, as vitórias e as derrotas de homens e mulheres que, em um determinado momento, fizeram as suas escolhas e foram, portanto, a carne e os ossos desta cidade.

\section{BIBLIOGRAFIA}

Abreu, Maurício de Almeida (2006). A Evolução urbana do Rio de Janeiro. Rio de Janeiro: IPP.

Abreu, Maurício de Almeida (2010). Geografia Histórica do Rio de Janeiro (1502-1700). Rio de Janeiro: Andrea Jakobsson Estúdio \& Prefeitura do Município do Rio de Janeiro.

Anderson, Benedict (2008). Comunidades Imaginadas: reflexões sobre a origem e a difusão do nacionalismo. Trad. Denise Bottman. São Paulo: Cia. Das Letras.

Benchimol, Jaime Larry (1990). Pereira Passos: um Haussmann tropical. A renovação urbana da cidade do Rio de Janeiro no início do século XX. Rio de Janeiro: Secretaria Municipal de Cultura, Turismo e Esportes, Departamento Geral de Documentação e Informação Cultural, Divisão de Editoração.

Burke, Peter (2005). o que é História Cultural. Rio de Janeiro: Zahar.

Cândido, Antônio (1985). Literatura e Sociedade. São Paulo: Cia Editora Nacional. 
Carvalho, Carlos Delgado de (1988). História da cidade do Rio de Janeiro (1884-1980). Rio de Janeiro: Secretaria Municipal de Cultura, Departamento Geral de Documentação e Informação Cultural. 126p. (Biblioteca Carioca)

Certeau, Michel de (1982). A Escrita da História. Tradução: Maria de Lourdes Menezes. Rio de Janeiro: Forense Universitária.

Certeau, Michel de (1995). A Cultura no Plural. Tradução: Enid Abreu Dobransky. Campinas: Papirus.

Certeau, Michel de (2014). A Invenção do Cotidiano. Tradução: Ephraim Ferreira Alves. Petrópolis RJ: Editora Vozes, 2014. Vol. 1 e 2.

Haesbaert, Rogério; Fridman, Fania (2014). Escritos sobre espaço e história. Rio de Janeiro: Garamond.

Le Goff, Jacques (2003). História e Memória. Tradução de Bernardo Leitão. Campinas: Editora da UNICAMP.

Lorenzo, Helena Carvalho de; Costa, Wilma Peres da (1997). A década de 20 e as origens do Brasil moderno. São Paulo: Fundação Editora da UNESP.

Machado, Lia Osório (1995). “Origens do Pensamento Geográfico no Brasil: meio tropical, espaços vazios e a ideia de ordem (1870-1930)". In: Castro, Iná Elias; Gomes, Paulo César Costa; Corrêa, Roberto Lobato (Orgs.) Geografia: Conceitos e Temas. Rio de Janeiro: Bertrand Brasil.

Machado, Lia Osório (2000). “As Ideias no Lugar. O Desenvolvimento do Pensamento Geográfico no Brasil no Início do Século XX”. Terra Brasilis. Geografia e Pensamento Social Brasileiro, julho/ dezembro.

Massey, Doreen B. (2009). Pelo Espaço: uma nova política da espacialidade. Rio de Janeiro: Bertrand do Brasil.

Needell, Jeffrey D. (1993). Belle Époque Tropical: Sociedade e cultura de elite no Rio de Janeiro na virada do século. Tradução: Celso Nogueira. São Paulo: Cia das Letras.

Rama, Ángel (2015). A Cidade das Letras. Tradução de Emir Sader. São Paulo: Boitempo.

Sevcenko, Nicolau (1999). Literatura como Missão. Tensões Sociais e Criação Cultural na Primeira República. São Paulo: Brasiliense.

Zusman, Perla; Pereira, Sérgio (2000). "Entre a ciência e a política: um olhar sobre a geografia de Delgado de Carvalho”. Terra Brasilis, v.1, n.1, p.52-82.

\section{NOTAS}

1. Carvalho (1988).

2. Burke (2005: 57).

3. Carvalho (2008: 19).

4. Carvalho (1988: 21).

5. Ibidem. Loc. Cit.

6. Ibidem. Loc. Cit.

7. Anderson (2008).

8. Carvalho (1988: 21). 


\section{RESUMOS}

O artigo visa compreender o processo de constituição do saber sobre a história da cidade do Rio de Janeiro, levando em consideração não apenas as inclinações políticas de Delgado de Caralho e suas relações com eminentes figuras da cidade, mas também as estratégias narrativas do autor. Não buscamos, assim, integrar o pensador em uma categoria mais ampla de intelectuais no pensamento social brasileiro, nem tampouco tecer considerações sobre o período histórico em que o livro foi publicado. Ainda que estas questões não sejam negligenciadas, o artigo aborda a maneira pela qual o autor escreve a história da cidade, enfocando não só aspectos teóricos e metodológicos, mas também sua apropriação do saber histórico e geográfico de sua época sobre o lugar e o tempo a fim de se inserir na vida social, política e cultural da cidade do Rio de Janeiro. 0 artigo visa compreender como se construiu uma versão da história do Rio que se confundia com os ícones da cultura moderna da década de 1920. A formação intelectual de Delgado de Carvalho, os objetivos do livro, a concepção de como fazer história e geografia e a relação com figuras políticas do período ajudam a compreender a interpretação do autor sobre a história de um lugar: a cidade do Rio de Janeiro.

L'objectif de l'article est de comprendre le processus de constitution du savoir sur l'histoire de la ville de Rio de Janeiro, tenant compte, autre que des inclinaisons politiques de Delgado de Carvalho et ses relations avec des hauts responsables de la ville, des stratégies narratives de lauteur. Nous ne cherchons pas, ainsi, intégrer le penseur dans une catégorie plus étendue d'intellectuels dans la pansée sociale brésilienne, pas plus que tisser des considérations sur la période historique dans laquelle le livre a été publié. Même si ces questions ne sont pas négligées, l'article soulève la manière par laquelle l'auteur écris l'histoire de la ville, soulevant pas seulement des aspects théoriques et méthodologiques, mais aussi son appropriation du savoir historique et géographique de l'époque sur le lieu et le temps, afin de s`insérer dans la vie sociale, politique et culturelle de la ville de Rio de Janeiro. L'article a pour but de comprendre comment s'est construite une version de l'histoire de Rio qui s'est confondue avec les icones de la culture moderne des années 20. La formation intellectuelle de Delgado de Carvalho, les objectifs du livre, la conception de comment faire histoire et géographie et la relation avec des personnages politiques de la période ont aidé a comprendre l'interprétation de l’auteur sur l'histoire d’un lieu: la ville de Rio de Janeiro.

Este artículo intenta comprender la constitución del conocimiento histórico sobre la ciudad de Río de Janeiro, teniendo en cuenta no sólo la inclinación política de Delgado de Carvalho y sus relaciones con eminentes figuras de la ciudad, sino también las estrategias narrativas del autor. De esta manera, en lugar de situar el investigador en una categoría de intelectuales del pensamiento social brasileño y poner en relieve aspectos del período histórico en que se publicó el libro, resaltamos la manera en que Delgado de Carvalho escribe la historia de la ciudad, considerando no sólo sus aportes teóricos y metodológicos sino también su apropiación del saber histórico y geográfico acumulado sobre el Río de Janeiro, logrando insertarse en la vida social, política y cultural de la ciudad. El artículo pretende comprender cómo se construyó una versión de la historia de Río que se confundía con los iconos de la cultura moderna de la década de 1920. La formación intelectual de Delgado de Carvalho, los objetivos del libro, la concepción de cómo hacer historia y geografía y la relación del autor con las figuras políticas del período ayudan a comprender su interpretación sobre la historia de un lugar: la ciudad de Río de Janeiro.

The article aims to understand the process of knowledge formation on the history of the city of Rio de Janeiro. We do not take into account only the political inclinations of Delgado de Caralho 
and his relations with eminent city figures, but also the narrative strategies of the author. We do not seek to integrate the thinker into a broader category of intellectuals in Brazilian social thought, nor to consider considerations about the historical period in which the book was published. Even if these issues are considered, the article discusses the way in which the author writes the history of the city, focusing not only on theoretical and methodological aspects, but also his appropriation of the historical and geographic knowledge of his time about the place and the time to be inserted in the social, political and cultural life of the city of Rio de Janeiro. The article aims to understand how a version of Rio de Janeiro's history was built in parallel with the icons of the modern culture of the 1920's. The intellectual formation of Delgado de Carvalho, the objectives of the book, the conception of how to make history and geography and the relationship with political figures of the period help to understand the author's interpretation of the history of a place: the city of Rio de Janeiro.

\section{ÍNDICE}

Índice geográfico: Rio de Janeiro

Palavras-chave: Delgado de Carvalho, Rio de Janeiro, História das cidades

Palabras claves: Delgado de Carvalho, Río de Janeiro, Historia de las ciudades

Índice cronológico: 1920

Keywords: Delgado de Carvalho, Rio de Janeiro, History of cities

Mots-clés: Delgado de Carvalho, Rio de Janeiro, Histoire des villes

\section{AUTOR}

\section{LEONARDO CIVALE}

Professor do Departamento de Geografia da Universidade Federal de Viçosa, Minas Gerais. civale@ufv.br 